\title{
ATRIBUTOS FÍSICOS DE UM NITOSSOLO VERMELHO CULTIVADO COM TRIGO, EM SISTEMA PLANTIO DIRETO, SUBMETIDO À COMPACTAÇÃO E ESCARIFICAÇÃO ${ }^{1}$
}

\author{
Sonia Toigo ${ }^{2}$, João Alfredo Braida ${ }^{3}$, Jean Carlo Possenti ${ }^{4}$, Evandro Martin Brandelero ${ }^{5}$, Murilo Mesquita Baesso ${ }^{6}$
}

\section{RESUMO}

A compactação do solo é comumente observada em solos cultivados no sistema plantio direto, podendo causar reduções na produtividade das culturas devido às limitações no crescimento radicular. O estudo objetivou avaliar a influência de níveis de compactação do solo, na produtividade de trigo cultivado em um Nitossolo Vermelho distroférrico úmbrico. O experimento foi realizado na Estação Experimental da Universidade Tecnológica Federal do Paraná (UTFPR), Campus Dois Vizinhos, PR, Brasil. Os tratamentos consistiram: sistema do plantio direto (PD), plantio direto com compactação adicional (PDA) e plantio direto com escarificação mecânica (PDE). Avaliou-se a densidade, a porosidade e a resistência do solo a penetração a cada $0,05 \mathrm{~m}$ até a profundidade de $0,25 \mathrm{~m}$, bem como a produtividade do trigo, a massa de grãos e o peso hectolitro. Constatou-se que na camada superficial do solo ocorreram as menores densidades de solo (Ds), maior macroporosidade e porosidade total nas três situações, sendo que nas camadas inferiores a 0,05 m os tratamentos PD e PDA, superaram o valor crítico $1,30 \mathrm{~kg} \mathrm{dm}^{-3}$ para solos muito argilosos. A compactação adicional ao sistema plantio direto afetou negativamente as propriedades físicas do solo, na sua camada superficial, acima de $0,05 \mathrm{~m}$, sendo observados incrementos de densidade do solo, na resistência à penetração e redução da macroporosidade e porosidade total. A escarificação mecânica melhorou as propriedades físicas do solo até a profundidade de $0,1 \mathrm{~m}$, após treze meses de intervenção, superando os demais sistemas avaliados. Entretanto, o uso do implemento subsolador, como forma de reduzir a compactação do solo, não contribuiu para o aumento da produtividade e a qualidade dos grãos de trigo.

Palavras-chave: triticum aestivum, sistemas de manejo, porosidade do solo

\section{ABSTRACT \\ PHYSICAL ATTRIBUTES OF AN OXISOL CROPPED WITH WHEAT IN NO-TILLAGE SYSTEM, SUBJECTED TO COMPACTION AND SCARIFICATION}

Soil compaction is commonly observed in cultivated no-tillage soils, and may cause reductions in crop yields due to limited root growth. This study aimed to evaluate the influence of different levels of soil compaction on wheat yield grown in an Oxisol (Nitossolo Vermelho distroférrico - Brazilian Soil Classification System). The experiment was conducted at the Experimental Station of the Federal Technological University of Paraná (UTFPR), Campus Dois Vizinhos, PR, Brazil. The treatments consisted of: no-tillage (PD), tillage with additional compression (PDA) and tillage with mechanical scarification (PDE). We evaluated the density, porosity and resistance to penetration at every $0.05 \mathrm{~m}$ to $0.25 \mathrm{~m}$ in depth, as well as the productivity of wheat, grain weight and hectoliter weight. It was found that in the topsoil are the lowest soil densities (Ds), greater macroporosity and total porosity at the three situations, where in the layers below $0.05 \mathrm{~m}$ the treatments PD and PDA exceeded the critical value of $1.30 \mathrm{~kg} \mathrm{dm}^{-3}$ for clayey soils. Additional compaction to the no-tillage system adversely affected the physical properties of the soil in the topsoil above $0.05 \mathrm{~m}$, where increases in the soil density, penetration resistance and reduced macroporosity and total porosity were observed. The mechanical scarification improved the physical properties of the soil to a depth of $0.1 \mathrm{~m}$ after thirteen months of intervention, outperforming the other systems. However, the use of a subsoiler to reduce soil compaction did not contribute to increased productivity and quality of wheat grain.

Keywords: triticum aestivum, soil management systems, soil porosity

\section{Recebido para publicação em 20/03/2014. Aprovado em 23/06/2014.}

1 - Parte da dissertação de Mestrado da primeira autora apresentada ao Programa de Pós Graduação em Agronomia da UTFPR,

2 - Engenheira Agrônoma, Mestre em Agronomia da UTFPR-PB / Pato Branco-PR, E-mail: sonia_toigo@hotmail.com

3 - Engenheiro Agrônomo, Doutor em Solos, UFFS / Chapecó-SC, E-mail: braida@uffs.edu.br

4 - Engenheiro Agrônomo, Doutor em Agronomia, UTFPR-DV / Dois Vizinhos-PR, E-mail: jpossenti@utfpr.edu.br

5 - Engenheiro Agrônomo, Doutor em Agronomia. UTFPR-DV / Dois Vizinhos-PR, E-mail: ebrandelero@utfpr.edu.br

6 - Engenheiro Agrônomo, Doutor em Engenharia Agrícola. USP / Pirassununga-SP, E-mail: baesso@usp.br 


\section{INTRODUÇÃO}

A cultura do trigo possui acentuada importância econômica e estratégica para o Brasil, uma vez que é a principal fonte de amido para a panificação. $\mathrm{O}$ país produziu na safra de 2013, aproximadamente, 5,47 milhões de toneladas de grãos de trigo, contra um consumo anual próximo de 11 milhões de toneladas, necessitando da importação anual de 6,5 milhões de toneladas (CONAB, 2014).

Constata-se que $90 \%$ da área semeada com trigo no estado do Paraná é sob o sistema plantio direto (SPD) e mais de $50 \%$ para os demais grãos no Brasil (IGNACZAK et al., 2005). O SPD é comprovadamente eficaz no controle das perdas de solo por erosão hídrica (AMARAL et al., 2008). Entretanto, o aumento do tráfego de máquinas e o pisoteio pelos animais com pastejo em solo sob SPD imprimem ao solo a degradação estrutural com redução da porosidade total e da macroporosidade, elevação da densidade do solo e da resistência à penetração, resultando na formação da compactação (TORMENA et al., 2004; TOIGO et al., 2007; REINERT et al., 2008).

A compactação do solo é a compressão do solo devido à aplicação de uma força que, num primeiro momento, rearranja e depois desorganiza os agregados, aumentando a sua densidade e reduzindo a sua porosidade (BOTTA, 2005), afetando as condições ideais para o desenvolvimento e crescimento vegetal por agir indiretamente na disponibilidade de água, na temperatura, na aeração, na resistência à penetração e no fluxo de nutrientes (LETEY, 1985), atuando negativamente na produtividade de grãos da cultura do trigo (SECCO et al., 2009).

Entretanto, o conhecimento dos limites críticos da compactação do solo ligadas ao desenvolvimento das plantas é uma importante informação para compreensão do SPD, pois permite avaliar a real necessidade das intervenções na mobilização do solo, seja por operações mecânicas ou pelo uso de coberturas verdes, melhorando o suprimento e difusão do oxigênio, a infiltração, armazenamento e disponibilidade de água para as plantas (ABREU et al., 2004).

A escarificação mecânica reduz os efeitos negativos da compactação, diminuindo a densidade e a resistência do solo à penetração (ABREU et al., 2004), melhorando o ambiente do solo para o armazenamento e movimento de água, fatores que promovem maiores produtividades (VEIGA et al., 2008). Camara e klein (2005), verificaram que a escarificação resultou em uma capacidade significativamente maior de condução da água, com valores oito vezes superiores ao solo sob plantio direto. Entretanto, para Girardello et al. (2011), o efeito da escarificação é efêmero, pois transcorridos apenas sete meses, verificaram decréscimo na infiltração de água no solo. DiazZorita (2000) e Akinci et al. (2004) verificaram que os efeitos da escarificação desapareceram a partir do segundo ano.

Neste contexto, partindo da hipótese de que a produtividade das culturas é determinada pelo grau de compactação do solo, devido às alterações nas propriedades físicas, implantou-se o trabalho com o objetivo de avaliar a influência de níveis de compactação do solo na produtividade de grãos de trigo (Triticum aestivum L.) cultivado em um Nitossolo Vermelho.

\section{MATERIAL E MÉTODOS}

O experimento foi realizado na Estação Experimental do Campus da Universidade Tecnológica Federal do Paraná - UTFPR, em Dois Vizinhos, PR. O solo é classificado como Nitossolo Vermelho distroférrico úmbrico (BHERING et al., 2008), com teores médios de argila, silte e areia de 660,320 e $20 \mathrm{~g} \mathrm{~kg}^{-1}$, respectivamente, e densidade de partículas média de $2,30 \mathrm{~kg} \mathrm{dm}^{-3}$. A área experimental na qual foi implantado o trabalho estava sob o sistema plantio direto há 10 anos com rotação das culturas, no inverno com trigo / aveia e no verão, milho / soja, empregando tráfego de máquinas como a semeadura, pulverização, aplicação de fertilizantes em cobertura e colhedora autopropelida de grãos.

O delineamento experimental foi o de blocos casualizados com três repetições, utilizando-se o trigo como cultura indicadora. As parcelas possuíam as dimensões de 5,5 x $16 \mathrm{~m}$ com área total de 88 $\mathrm{m}^{2}$. Os tratamentos foram implantados em maio de 2008 e consistiram de: sistema do plantio direto (PD), plantio direto com compactação adicional 
(PDA) e plantio direto com escarificação mecânica (PDE).

No tratamento PD, manteve-se o solo nas mesmas condições em que vinha sendo cultivado antes do experimento, sem nenhum efeito adicional. Para a compactação adicional no tratamento PDA, foi utilizando um trator John Deere ${ }^{\circledR}$ modelo 5600 dotado de tração dianteira auxiliar, com massa em ordem de embarque de $4.500 \mathrm{~kg}$, pneus dianteiros 9,5x24R1 e traseiros 14,9x24R1, tendo acoplado um pulverizador Jacto $^{\circledR}(250 \mathrm{~kg})$, montado e abastecido com 600 litros de água. A compactação adicional foi realizada quando o solo estava com conteúdo de água da ordem de $0,14 \mathrm{~kg} \mathrm{~kg}^{-1}$, correspondente a máxima densidade obtida para a condição do solo, obtidos em estudos anteriores (BRAIDA et al., 2006). O referido conteúdo de água no solo foi obtido logo após período de chuva, monitorando-se o solo utilizando a técnica da umidade gravimétrica descrita pela Embrapa (1997).

A partir da confirmação do momento para a realização da adição da compactação do solo, efetuou-se a passagem com o trator seis vezes sobre o mesmo local e em toda a área da parcela. No tratamento PDE, a escarificação correspondeu em uma única passagem de um subsolador da marca Jumil ${ }^{\circledR}$ com cinco hastes parabólicas espaçadas em $0,50 \mathrm{~m}$, trabalhando na profundidade de $0,25 \mathrm{~m}$, tracionados pelo mesmo trator utilizado para a compactação adicional sem a adição do pulverizador. As hastes possuíam formato reto inclinado, largura da haste de $0,036 \mathrm{~m}$ e da ponteira $0,076 \mathrm{~m}$, ângulo de ataque da haste de $45^{\circ} \mathrm{e}$ da ponteira $20^{\circ}$.

Após a implantação dos tratamentos nas parcelas, estas permaneceram em pousio, desenvolvendo-se a vegetação espontânea. Posteriormente, em novembro de 2008, foi implantada a cultura do milho em todas as parcelas, cujo ciclo estendeu-se até fevereiro de 2009, quando se realizou a colheita dos grãos de milho não discutidos neste trabalho.

A implantação com a cultura do trigo, cultivar BRS 220, foi realizada em junho de 2009, com espaçamento de $0,17 \mathrm{~m}$ nas entrelinhas e com densidade de 80 plantas por metro, utilizandose uma semeadora - adubadora para plantio direto, marca Imasa ${ }^{\circledR}$, com discos duplos desencontrados. As sementes receberam tratamento com fungicida à base de triadimenol e inseticida à base de imidacloprid. Utilizouse adubação de base constituída de $400 \mathrm{~kg} \mathrm{ha}^{-1}$ do formulado 08-20-20 (NPK). A adubação em cobertura foi de $100 \mathrm{~kg} \mathrm{ha}^{-1}$ de uréia, aplicados em julho de 2009 durante o estágio de perfilhamento do trigo.

Monitorou-se a distribuição das chuvas ocorridas na área durante o período experimental até o final do ciclo de desenvolvimento do trigo, ou seja, entre os meses de maio de 2008 a outubro de 2009 (Figura 1).

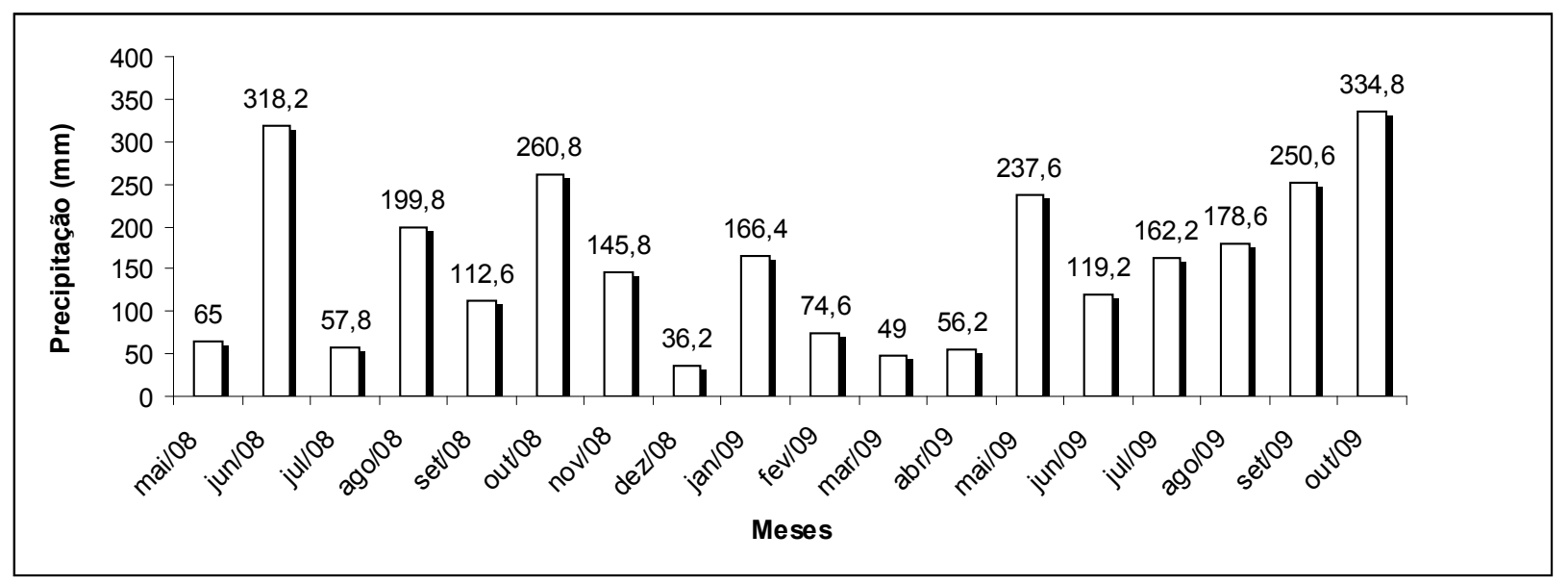

Figura 1. Precipitação pluvial mensal na Estação Experimental da UTFPR, observada no período do experimento. 
Realizou-se a coleta de amostras indeformadas, com estrutura preservada nas camadas com profundidades entre: 0 a 0,$05 ; 0,05$ a 0,$10 ; 0,10$ a 0,$15 ; 0,15$ a 0,$20 ; 0,20$ a $0,25 \mathrm{~m}$, usando um cilindro volumétrico de aço inoxidável com, aproximadamente, $8,5 \cdot 10^{-5} \mathrm{~m}^{3}$ de volume $(0,06$ $\mathrm{m}$ de diâmetro por $0,03 \mathrm{~m}$ de altura). Coletaramse, no dia 31 de julho de 2009, três amostras por profundidade e para cada parcela, totalizando nove amostras por tratamento. Após as coletas, as amostras foram encaminhadas para o Laboratório de Solos da UTFPR, os quais subsidiaram a quantificação da densidade e da porosidade do solo através da metodologia descrita pela Embrapa (1997). Considerou-se como porosidade total $(\mathrm{Pt})$, o volume de água contido na amostra saturada e como microporosidade (Pmi) do solo, o volume de água retido após aplicação de sucção de $6 \mathrm{kPa}$ na mesa de tensão. A macroporosidade (Pma) foi obtida pela diferença entre a Pt e a Pmi.

$\mathrm{Na}$ mesma data da coleta das amostras de solo, mediu-se a resistência do solo à penetração com o uso de um penetrômetro eletrônico marca Eijkelkanp ${ }^{\circledR}$ com ponta (cone) de $1 \mathrm{~cm}^{2}$ de área. As medições foram feitas em cinco repetições por parcela, sendo suas leituras registradas verticalmente a cada $0,05 \mathrm{~m}$ até a profundidade de 0,25 m.

Para avaliação da produtividade do trigo, considerou-se a produção total de grãos, coletandose todas as panículas numa área de $4 \mathrm{~m}^{2}$ no centro de cada parcela. Após a coleta, fez-se a debulha usando uma trilhadora de parcelas, determinandose a massa de grãos que foi expressa em $\mathrm{kg} \mathrm{ha}^{-1}$ com umidade corrigida para 13\%. Determinouse, também, o peso do hectolitro, utilizando-se uma balança de peso específico e o peso de mil grãos, mediante a pesagem de oito amostras de 100 sementes, de acordo com as Regras de Análise de Sementes (BRASIL, 2009).

A análise estatística dos dados foi realizada por meio do programa computacional Sanest (ZONTA et al., 1984), fazendo-se a análise de variância e teste $\mathrm{F}$ com $1 \%$ de significância. Nos casos em que encontrou variância significativa, a mesma foi complementada pelo teste de média de Duncan 1\%.

\section{RESULTADOS E DISCUSSÃO}

Os maiores valores de densidade do solo (Ds) ocorreram no solo sob PDA nas profundidades entre 0,0 a 0,05, 0,05 a 0,10 m e 0,15 a 0,20 (Quadro 1). Na camada de 0,0 a $0,05 \mathrm{~m}$ de profundidade os valores médios de densidade do solo para os níveis de compactação foram respectivamente de 1,08, 1,09 e 1,20 $\mathrm{kg} \mathrm{dm}^{-3}$ para PDE, PD e PDA, sendo o valor no PDA significativamente maior que os demais.

Acamada superficial, acima de $0,05 \mathrm{~m}$ apresentou os menores valores de Ds e, consequentemente, a maior porosidade total e maior macroporosidade no perfil do solo para os sistemas de manejo. Isso ocorre em função do maior acúmulo de matéria orgânica (CAMPOS et al., 2011) e escarificação biológica do solo nas camadas superficiais do solo sob plantio direto (NEIRO et al., 2003; FERREIRA et al., 2007). Também, por ocasião da implantação das culturas (normalmente duas ao ano), a camada superficial sofre uma movimentação do solo causada pelas hastes sulcadoras das semeadoras (GENRO JUNIOR et al., 2004), contribuindo para redução de sua densidade do solo.

A escarificação realizada no PDE reduziu a Ds até a profundidade de $0,10 \mathrm{~m}$, diferenciando do tratamento com compactação adicional (PDA), possivelmente pelo efeito da desagregação do solo promovida pelas hastes sulcadoras do subsolador após treze meses da implantação. Estes resultados não correspondem aos obtidos por Drescher et al. (2011), que, trabalhando também com o mesmo implemento no sistema plantio direto, obtiveram melhoria nos atributos físicos do solo logo após o seu preparo mas que desapareceram em poucos ciclos de cultivo. Contudo, os autores verificaram que os resultados foram similares ao da área mantida sob SPD após quatro anos de cultivo, atribuindo tal efeito ao processo natural de reconsolidação do solo, resultante da chuva e dos ciclos de umedecimento e secagem.

A partir da profundidade de $0,05 \mathrm{~m}$, a Ds (Quadro 1) nos tratamentos PD e PDA, superaram o valor crítico $1,30 \mathrm{~kg} \mathrm{dm}^{-3}$, conforme indicado por Reichert et al. (2003) para solos muito argilosos como o do presente trabalho e, portanto, indica a existência de compactação excessiva no solo. 
Quadro 1.Efeito do manejo do solo na densidade do solo $\left(\mathrm{kg} \mathrm{dm}^{-3}\right)$, macroporosidade (Pma), microporosidade (Pmi) e porosidade total $(\mathrm{Pt}) \mathrm{em} \mathrm{m}^{3} \mathrm{~m}^{-3} \mathrm{em}$ função da profundidade de um Nitossolo Vermelho distroférrico úmbrico sob sistema do plantio direto (PD), plantio direto com compactação adicional (PDA) e plantio direto com escarificação mecânica (PDE).

\begin{tabular}{|c|c|c|c|c|}
\hline \multirow[b]{2}{*}{ Manejo do solo } & \multirow{2}{*}{$\begin{array}{l}\text { Densidade } \\
\left(\mathrm{kg} \mathrm{dm}^{-3}\right)\end{array}$} & \multicolumn{3}{|c|}{ Porosidade $\left(\mathrm{m}^{3} \mathrm{~m}^{-3}\right)$} \\
\hline & & Pma & Pmi & $\mathrm{Pt}$ \\
\hline & \multicolumn{4}{|c|}{ Profundidade $0,0-0,05 \mathrm{~m}$} \\
\hline PDE & $1,08 \mathrm{~b}^{1}$ & $0,308 \mathrm{a}$ & $0,392^{\mathrm{ns}}$ & $0,703 \mathrm{a}$ \\
\hline PD & $1,09 \mathrm{~b}$ & $0,301 \mathrm{a}$ & 0,397 & $0,693 \mathrm{a}$ \\
\hline PDA & $1,20 \mathrm{a}$ & $0,209 \mathrm{~b}$ & 0,436 & $0,648 \mathrm{~b}$ \\
\hline \multirow[t]{2}{*}{ C.V. (\%) } & 1,25 & 10,10 & 5,80 & 2,64 \\
\hline & \multicolumn{4}{|c|}{ Profundidade $0,05-0,10 \mathrm{~m}$} \\
\hline PDE & $1,19 \mathrm{~b}$ & $0,230^{\mathrm{ns}}$ & $0,421^{\mathrm{ns}}$ & $0,656 \mathrm{a}$ \\
\hline PD & $1,31 \mathrm{ab}$ & 0,255 & 0,437 & $0,615 \mathrm{ab}$ \\
\hline PDA & $1,33 \mathrm{a}$ & 0,234 & 0,445 & $0,604 \mathrm{~b}$ \\
\hline \multirow[t]{2}{*}{ C.V. (\%) } & 2,16 & 18,33 & 5,11 & 4,02 \\
\hline & \multicolumn{4}{|c|}{ Profundidade $0,10-0,15 \mathrm{~m}$} \\
\hline PDE & 1,27 ns & $0,209 \mathrm{a}$ & $0,438^{\text {ns }}$ & $0,653 \mathrm{a}$ \\
\hline $\mathrm{PD}$ & 1,35 & $0,136 \mathrm{~b}$ & 0,458 & $0,595 \mathrm{~b}$ \\
\hline PDA & 1,33 & $0,151 \mathrm{ab}$ & 0,435 & $0,590 \mathrm{~b}$ \\
\hline \multirow[t]{2}{*}{ C.V. $(\%)$} & 1,84 & 16,50 & 4,23 & 3,58 \\
\hline & \multicolumn{4}{|c|}{ Profundidade $0,15-0,20 \mathrm{~m}$} \\
\hline PDE & $1,30^{\mathrm{ns}}$ & $0,184^{\mathrm{ns}}$ & $0,436^{\mathrm{ns}}$ & $0,623^{\mathrm{ns}}$ \\
\hline PD & 1,32 & 0,137 & 0,465 & 0,601 \\
\hline PDA & 1,36 & 0,132 & 0,446 & 0,587 \\
\hline \multirow[t]{2}{*}{ C.V. (\%) } & 1,77 & 16,68 & 3,71 & 5,77 \\
\hline & \multicolumn{4}{|c|}{ Profundidade $0,20-0,25 \mathrm{~m}$} \\
\hline PDE & $1,26^{\mathrm{ns}}$ & $0,165^{\mathrm{ns}}$ & $0,461^{\text {ns }}$ & $0,629^{\text {ns }}$ \\
\hline PD & 1,29 & 0,141 & 0,470 & 0,612 \\
\hline PDA & 1,29 & 0,143 & 0,471 & 0,619 \\
\hline C.V. (\%) & 1,58 & 16,8 & 3,97 & 4,00 \\
\hline
\end{tabular}

${ }^{1}$ Médias seguidas por letras distintas na coluna, em cada profundidade, diferem significativamente entre si pelo teste Duncan a $1 \%$ de significância. ${ }^{\text {ns }}$ Variância não significativa, pelo teste $\mathrm{F}$ a $1 \%$ de significância.

A macroporosidade mostrou variação significativa em função dos tratamentos e da profundidade avaliada (Quadro 1). Maiores valores foram observados na camada entre 0 a $0,05 \mathrm{~m}$, na qual o PDE apresentou valores superiores ao PDA. Nas camadas subjacentes, observaram-se valores menores de macroporosidade em todos os tratamentos, de forma semelhante ao observado por
Veiga et al. (2008), com uma tendência de valores maiores no solo escarificado.

Entretanto, nos três tratamentos e em todas as camadas avaliadas, a macroporosidade permaneceu acima de $0,10 \mathrm{~m}^{3} \mathrm{~m}^{-3}$, valor considerado como crítico para o desenvolvimento das plantas segundo Beltrame et al. (1981). Segundo os autores supracitados, quando a macroporosidade é menor do 
que este limite, a porosidade livre de água, ou seja, a porosidade de aeração é insuficiente para não ocorrer restrições ao bom desenvolvimento radicular.

De maneira geral, observaram-se que, em todos os tratamentos, as condições físicas foram inferiores nas profundidades entre 0,10 a $0,15 \mathrm{e}$ de 0,15 a $0,20 \mathrm{~m}$ (Quadro 1), quando avaliada pelos valores de porosidade total, condicionada pela redução de macroporos, visto que a microporosidade não foi afetada. Até os 0,15 $\mathrm{m}$ de profundidade, o PDA apresentou valores de porosidade total inferiores aos observados no PDE, enquanto que o PD apresentou valores intermediários. Tal condição pode ter implicações sobre a infiltração de água no perfil, fenômeno importante para maior armazenamento de água no solo, além de comprometer o crescimento de raízes em anos com escassez de precipitações, onde as mesmas necessitam se aprofundar para absorver água e nutrientes.

A resistência do solo à penetração (RP) apresentou variância significativa em função dos tratamentos utilizados para todas as profundidades estudadas (Figura 2), demonstrando ser o parâmetro mais sensível na detecção da compactação, corroborando com a observação de Abreu et al. (2004). O PDA apresentou valores de RP superiores para todas as profundidades em relação ao PDE e ao PD na camada superficial (0 a $0,05 \mathrm{~m})$. Importante observar que os tratamentos PD e PDA apresentaram valores superiores a $2 \mathrm{MPa}$, valor considerado como limitante para o crescimento e desenvolvimento do sistema radicular (NEIRO et al., 2003), a partir da profundidade de $0,05 \mathrm{~m}$. O tratamento com escarificação, ainda que tenha apresentado valores menores, também superou $2 \mathrm{MPa}$ a partir de $0,10 \mathrm{~m}$ de profundidade.

Os resultados apresentados indicam que as propriedades físicas do solo, especialmente a resistência à penetração, ainda refletem os efeitos dos tratamentos aplicados no início do experimento (13 meses antes das avaliações). De certo modo, estes dados corroboram as observações de DiazZorita (2000) eAkincietal.(2004), que verificaram que os efeitos da subsolagem desapareceram,

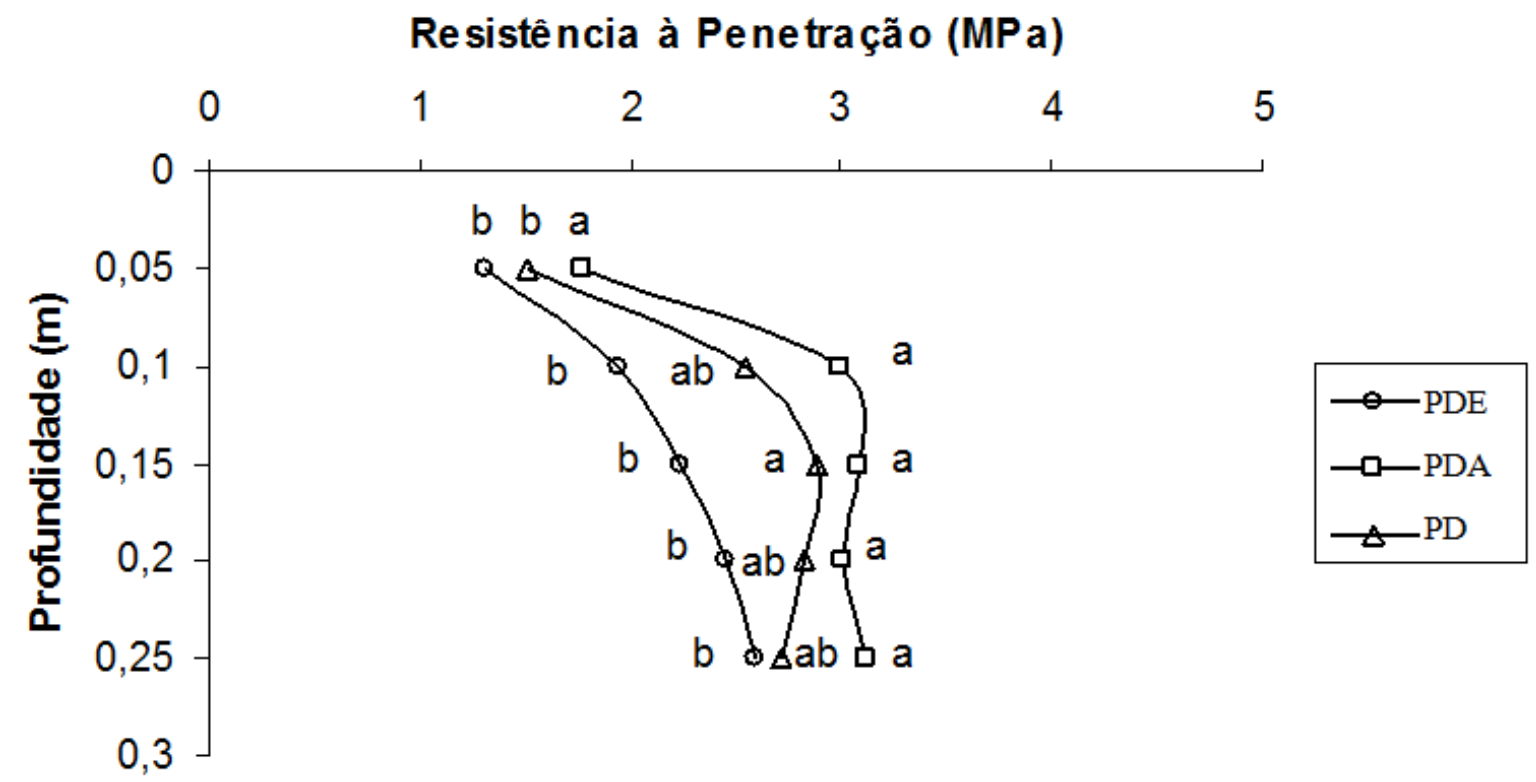

Figura 2. Efeito dos manejos do solo na resistência à penetração (MPa) de um Nitossolo Vermelho distroférrico úmbrico sob sistema do plantio direto (PD), plantio direto com compactação adicional (PDA) e plantio direto com escarificação mecânica (PDE). Letras distintas na mesma profundidade indicam médias significativamente diferentes pelo teste Duncan a $1 \%$. 
quase completamente, à partir do segundo ano de sua realização em solos de textura argilosa. Pikul Jr. \& Aase (1999), trabalhando com um solo franco-arenoso, verificaram a homogeneização após dois anos e meio.

Os sistemas de manejo do sistema do plantio direto não atuaram na produtividade e na qualidade dos grãos de trigo (Quadro 2). Assim, é possível inferir que o nível de compactação obtidos no PD e PDA, que proporcionaram Ds maiores que $1,30 \mathrm{~kg} \mathrm{dm}^{-3}$ e RP maiores que $2 \mathrm{Mpa}$ a partir de 0,05 $\mathrm{m}$ de profundidade, não comprometeram a cultura do trigo. A não diferenciação entre os tratamentos quanto à produtividade e o peso hectolitro pode ter sido condicionada pelas frequentes e abundantes precipitações pluviométricas observadas no período de desenvolvimento da cultura (Figura 1), o que possivelmente não permitiu a manifestação dos efeitos negativos da compactação nos tratamentos PD e PDA, especialmente por permitir um adequado fornecimento de água à cultura. A produtividade média observada no experimento $\left(1.860 \mathrm{~kg} \mathrm{ha}^{-}\right.$ $\left.{ }^{1}\right)$ situa-se pouco abaixo da média observada no Estado do Paraná em 2009, que foi de $1.920 \mathrm{~kg}$ ha $^{-1}$ (DERAL, 2014).

$\mathrm{O}$ peso do hectolitro $(\mathrm{PH})$ variou entre 67,7 e $69,2 \mathrm{~kg} \mathrm{hL}^{-1}$ entre os diferentes manejos do sistema plantio direto (Quadro 2), não havendo variância significativa. Estes valores de $\mathrm{PH}$ estão abaixo da classificação recomendada para a comercialização de trigo, que é de 78. Os elevados valores de pluviosidade que ocorreram durante o mês de outubro de 2009 (Figura 1), período de maturação em campo das espigas no ensaio, possivelmente contribuíram para estes resultados. Segundo Guarienti et al. (2005), a diminuição do peso hectolitro pode ser atribuída às mudanças sucessivas de umidade dos grãos, com ciclos de secagem e umedecimento em campo, ocasionados por períodos chuvosos muito longos.

A ocorrência de correlações negativas entre elevada umidade relativa do ar e excesso hídrico do solo sobre o peso de mil grãos, peso hectolitro e produtividade de grãos durante os períodos que antecedem a colheita, também é observada no trabalho realizado por Guarienti et al. (2005). Segundo os autores, sob condições de elevada umidade relativa, o processo transpiratório de uma planta túrgida é mínimo, não ocorrendo fluxo de água na mesma, consequentemente de nutrientes. Tal condição resulta em redução dos produtos fotossintéticos como carboidratos, lipídios, aminoácidos, responsáveis pelo enchimento de grãos, de forma que os grãos se tornam menores, influenciando nas variáveis de peso de mil grãos e peso hectolitro, determinantes da produtividade de grãos.

Quadro 2. Qualidade da produção de grãos de trigo expressos em produtividade $\left(\mathrm{kg} \mathrm{ha}^{-1}\right)$, peso de mil grãos (g) e peso do hectolitro $\left(\mathrm{kg} \mathrm{hL}^{-1}\right)$ cultivado em Nitossolo Vermelho distroférrico úmbrico sob diferentes efeitos de manejos de solo.

\begin{tabular}{lccc}
\hline Manejo do solo & $\begin{array}{c}\text { Produtividade } \\
\left(\mathrm{kg} \mathrm{ha}^{-1}\right)\end{array}$ & $\begin{array}{c}\text { Peso de mil grãos } \\
(\mathrm{g})\end{array}$ & $\begin{array}{c}\text { Peso hectolitro } \\
\left(\mathrm{kg} \mathrm{hL}^{-1}\right)\end{array}$ \\
\hline PDE & $1.930^{\mathrm{ns}}$ & $329,1^{\mathrm{ns}}$ & $69,2^{\mathrm{ns}}$ \\
PD & 1.870 & 295,2 & 68,3 \\
PDA & 1.750 & 330,0 & 67,7 \\
\hline Média & 1.850 & 318,1 & 68,4 \\
\hline C.V.(\%) & 11,30 & 7,30 & 1,38 \\
\hline
\end{tabular}

${ }^{\text {ns }}$ variância não significativa pelo teste $\mathrm{F}$ a 5\% de significância 


\section{CONCLUSÕES}

- A compactação adicional ao sistema plantio direto afetou negativamente as propriedades físicas do solo na sua camada superficial, sendo então observados incrementos de densidade, na resistência à penetração e redução da macroporosidade e porosidade total;

- A escarificação mecânica melhorou as propriedades físicas do solo na camada superficial, treze meses após a intervenção, superando os demais sistemas avaliados;

- O uso do subsolador como forma de reduzir a compactação do solo não contribuiu para o aumento da produtividade e qualidade dos grãos de trigo.

\section{REFERÊNCIAS BIBLIOGRÁFICAS}

ABREU, S.L.; REICHERT, J.M.; REINERT, D.J. Escarificação mecânica e biológica para a redução da compactação em Argissolo franco-arenoso sob plantio direto. Revista Brasileira de Ciência do Solo, Viçosa, MG, v.28, n.3, p.519-531, 2004.

AKINCI, I.; CAKIR, E.; TOPAKCI, M.; CANAKCI, M.; INAN, O. The effect of subsoiling on soil resistance and cotton yield. Soil \& Tillage Research, Amsterdam, v.77, n.3, p.203-210, 2004.

AMARAL, A.J.; BERTOL, I.; COGO, N.P.; BARBOSA, F.T. Redução da erosão hídrica em três sistemas de manejo do solo em um cambissolo húmico da região do planalto sul - catarinense. Revista Brasileira de Ciência do Solo, Viçosa, MG, v.32, n.5, p.2145-2155, 2008.

BELTRAME, L.F.S.; GONDIM, L.A.P.; TAYLOR, J.C. Estrutura e compactação na permeabilidade de solos do Rio Grande do Sul. Revista Brasileira de Ciência do Solo, Viçosa, MG, v.5, n.1, p.145-149, 1981.

BHERING, S.B.; SANTOS, H.G.DOS; BOGNOLA, I.A.; CÚRCIO, G.R.; MANZATTO, C.V.; CARVALHO JUNIOR, W.DE; CHAGAS,
C.DOSS.; ÁGLIO, M.L.D.; SOUZA, J.S. Mapa de solos do Estado do Paraná: legenda atualizada. Rio de Janeiro: EMBRAPA/IAPAR, 2008. 74p.

BRAIDA, J.A.; REICHERT, J.M.; VEIGA, M.; REINERT, D.J. Resíduos vegetais na superfície e carbono orgânico do solo e suas relações com a densidade máxima obtida no ensaio Proctor. Revista Brasileira de Ciência do Solo, Viçosa, MG, v.30, n.4, p.605-614, 2006.

Brasil Regras para análise de sementes. Brasília: Ministério da Agricultura, Pecuária e Abastecimento, 2009. 399p.

CAMARA, R.K.; KLEIN, V.A. Escarificação em plantio direto como técnica de conservação do solo e da água. Revista Brasileira de Ciência do Solo, Viçosa, MG, v.29, n.5, p.789-796, 2005.

CAMPOS, B.C.; AMADO, T.J.C.; BAYER, C.; NICOLOSO, R.S.; FIORIN, J.E. Carbon stock and its compartments in a subtropical oxisol under long-term tillage and cropping systems. Revista Brasileira de Ciência do Solo, Viçosa, MG, v.35, n.3, p.805-817, 2011.

CONAB - Companhia Nacional de Abastecimento. Acompanhamento da Safra Brasileira de Grãos. Brasília: CONAB. 67p. Disponível em: $<$ http://www.conab.gov.br/OlalaCMS/uploads/ arquivos/14_01_09_09_12_21_boletim_ portugues_janeiro_2014_(original).pdf $>$, Acesso em: 17 de junho de 2014.

DERAL - DEPARTAMENTO DE ECONOMIA RURAL Área e Produção Agrícola no Estado do Paraná por Unidade Administrativa da SEAB. Disponível em: <http://www.agricultura.pr.gov.br/ arquivos/File/deral/Tab_prod_inv.pdf $>$, Acesso em: 21 de maio de 2014.

DIAZ-ZORITA M. Effect of deep-tillage and nitrogen fertilization interactions on dryland corn (Zea mays L.) productivity. Soil \& Tillage Research, Amsterdam, v.54, n. 1/2, p.11-19, 2000. 
DRESCHER, M.S.; ELTZ, F.L.F.; DENARDIN, J.E.; FAGANELlO, A. Persistência do efeito de intervenções mecânicas para a descompactação de solos sob plantio direto. Revista Brasileira de Ciência do Solo, Viçosa, MG, v.35, n.5, p.713$1722,2011$.

EMBRAPA Centro Nacional de Pesquisa de Solos. Manual de métodos de análise de solos. $2^{\mathrm{a}}$ ed. Rio de Janeiro: EMBRAPA, 1997. 212p.

FERREIRA, E.A.B.; RESCK, D.V.S.; GOMES, A.C.; RAMOS, M.L.G. Dinâmica do carbono da biomassa microbiana em cinco diferentes épocas do ano em diferentes sistemas de manejo do solo no cerrado. Revista Brasileira de Ciência do Solo, Viçosa, MG, v.31, n.6, p.1625-1635, 2007.

GENRO JUNIOR, A.S.; REINERT, D.J.; REICHERT, J.M. Variabilidade temporal da resistência à penetração de um latossolo argiloso sob semeadura direta com rotação de culturas. Revista Brasileira de Ciência do Solo, Viçosa, MG. v.28, n.3, p.477-484, 2004.

GIRARDELLO, V.C.; AMADO, T.J.C.; NICOLOSO, R.DAS.; HÖRBE, T.DEA.N.; FERREIRA, A.DEO., TABALDI, F.M.; LANZANOVA, M.E. Alterações nos atributos físicos de um Latossolo Vermelho sob plantio direto induzidas por diferentes tipos de escarificadores e o rendimento da soja. Revista Brasileira de Ciência do Solo, Viçosa, MG, v.35, n.6, p.2115-2126, 2011.

GUARIENTI, E.M.; CIACCO, C.F.; CUNHA, G.R.; DEL DUCA, L.J.A.; CAMARGO, C.M.O. Efeitos da precipitação pluvial, da umidade relativa do ar e de excesso e déficit hídrico do solo no peso do hectolitro, no peso de mil grãos e no rendimento de grãos de trigo. Ciência e Tecnologia de Alimentos, Campinas, SP, v.25, n.3, p.412-418, 2005.

IGNACZAK, J.C.; MAURINA, A.C.; DE MORI, C.; FERREIRA FILHO, A. Uso de tecnologias em lavouras de trigo tecnicamente assistidas no Paraná - Safra 2005. Passo Fundo: Embrapa Trigo, 26p. Disponível em: <http://www.cnpt.embrapa.br/ biblio/bp/p_bp31.htm >, Acesso em: 06 de junho de 2013.

LETEY, J. Relationship between soil physical conditions and crop production. Advances in Soil Sciences, New York, v.1, n.3, p.277-293, 1985.

NEIRO, E.S.; MATA, J.D.V.; TORMENA, C.A.; GONÇALVES, A.C.A.; PINTRO, J.C.; COSTA, J.M. Resistência à penetração de um Latossolo Vermelho distroférrico, com rotação e sucessão de culturas sob plantio direto. Acta Scientiarum Agronomy, Maringa, PR, v.25, n.1, p.19-25, 2003.

PIKUL JR., J.L.; AASE, J.K. Wheat response and residual soil properties following subsoiling of a sandy loam in eastern Montana. Soil \& Tillage Research, Amsterdam, v.51, n.1, p.61-70, 1999.

REICHERT, J.M.; REINERT, D.J.; BRAIDA, J.A. Qualidade dos solos e sustentabilidade agrícola. Ciência e Ambiente, Santa Maria, RS, v.14, n.27, p.29-48, 2003.

REINERT, D.J.; ALBUQUERQUE, J.A.; REICHERT, J.M.; AITA, C.; ANDRADA, M.M.C. Limites críticos de densidade do solo para o crescimento de raízes de plantas de cobertura em Argissolo vermelho. Revista Brasileira de Ciência do Solo. Viçosa, MG, v.32, n.5, p.8051816, 2008.

SECCO, D.; REINERT, D.J.; REICHERT, J.M.; SILVA, V.R. Atributos físicos e rendimento de grãos de trigo, soja e milho em dois Latossolos compactados e escarificados. Ciência Rural, Santa Maria, RS, v.39, n.1, p.58-64, 2009.

TOIGO, S.; BRAIDA, J.A.; CARNIELETTO, C.E. Diagnóstico das condições químicas e físicas do solo em áreas sob plantio direto no município de Flor da Serra do Sul, PR. In: CONGRESSO BRASILEIRO DE CIÊNCIA DO SOLO, 31., 2007, Gramado. Anais... Gramado: Sociedade Brasileira de Ciência do Solo, 2007. CD-ROM.

TORMENA, C.A.; VIDIGAL FILHO, O.S.; GONÇALVES, A.C.A.; ARAÚJO, M.A.; 
PINTRO, J.C. Influência de diferentes sistemas de preparo do solo nas propriedades físicas de um Latossolo Vermelho distrófico. Revista Brasileira de Engenharia Agrícola e Ambiental, Campina Grande, PB, v.8, n.1, p.65-71, 2004.

VEIGA, M.DA; HORN, R.; EINERT, D.J.; REICHERT, J.M. Soil compressibility and penetrability of an Oxisol from southern Brazil, as affected by long-term tillage systems. Soil \& Tillage Research, Amsterdam, v.92, n.1, p.104113, 2006.
VEIGA, M.DA; REINERT, D.J.; REICHERT, J.M.; KAISER, D.R. Short and long-term effects of tillage systems and nutrient sources on soil physical properties of a Southern Brazilian Hapludox. Revista Brasileira de Ciência do Solo, Viçosa, MG, v.32, n.4, p.1437-1446, 2008.

ZONTA, E.P.; MACHADO, A.D.; SILVEIRA JUNIOR, P. Sistemas de análise estatística para microcomputadores - SANEST. Pelotas: UFPel, 1984.138p. 